\title{
Inhibition of Atrial Action Potentials Alternans by Calcium-Activated Chloride Current Blockade - Simulation Study
}

\author{
J Gomis-Tena, J Saiz, JM Ferrero (Jr)
}

\section{Centro de Investigación e Innovación en Bioingeniería, Universidad Politécnica de Valencia, Spain}

\begin{abstract}
Atrial fibrillation $(A F)$ is the most common cardiac arrhythmia. Atrial action potential (AP) alternans appearance during atrial flutter play a determinant role as AF precursor. AP alternans involves intracellular calcium concentration alternation that affects calcium dependent currents like $I_{\mathrm{NaCa}}$ and $I_{\mathrm{ClCa}}$. In this study, a modified rabbit atrial AP mode, that includes $I_{C l, C a}$ formulation is used. In order to induce alternans, the pacing cycle length was abruptly shortened from a basic drive of $1000 \mathrm{~ms}$ after $7.5 \mathrm{~s}$ of stimulation. The role of $I_{C I C a}$ was investigated by blocking the current. When increasing pace rate, from a cycle length of $1000 \mathrm{~ms}$ to $180 \mathrm{~ms}$, beat-to-beat alternans appear. Repeating the procedure in $I_{\mathrm{ClCa}}$ blockade situation, in the range of 60 to $100 \%$, alternans dessapear. Our results suggest that $I_{C l C a}$ blockade prevents alternans and for this reason $I_{C I C a}$ blockade could be potentially antiarrhythmic, preventing $A F$.
\end{abstract}

\section{Introduction}

Most people have a normal heart rhythm (sinus rhythm) rate of between 60 and 80 beats per minute. In atrial fibrillation, the atria contract rapidly and irregularly at rates of 400 to 600 beats per minute. The AV node will not allow many signals through to the ventricles; only 1:2 or 1:3 of atrial beats pass to ventricles. However, the ventricles beat too fast, at rates of 110 to 180 beats per minute.

AF is the most common cardiac arrhythmia affecting millions of people worldwide, its incidence increases with age and it is responsible for a substantial proportion of hospital costs incurred in the treatment of cardiac rhythm disorders [1]. AF treatment, depending on the case, could be based in antiarrhythmic and anticoagulant drugs or requires the use radiofrequency ablation and surgery [2].

AF mechanism is unknown. There are two main hypothesis: the multiple wavelet theory of Garrey and Moe [3] and the ectopic focus theory by Engelman [4].

It is known that alternans of atrial action potential (AP) during atrial flutter could play a determinant role as a precursor to $\mathrm{AF}$ [5].

Beat-to-beat alternans of AP could be observed on the surface like the appearance of electrocardiographic (ECG) $\mathrm{T}$-waves alternans that are characterized by beatto-beat alternation of the morphology, amplitude and/or polarity of the $\mathrm{T}$ wave.

Shimizu and Antzelevitch found that under conditions mimicking congenital long-QT syndrome physiology in a ventricular wedge preparation, alternans of ECG T-wave and action potential duration (APD) were elicited during rapid pacing and abolished by ryanodine and low extracellular calcium, implicating intracellular calcium cycling in the maintenance of alternans [6].

Leistad and co-workers investigated the contractile dysfunction in an experimental model of AF [7] and they found that the atrial contractile dysfunction after acute $\mathrm{AF}$ is reduced by the calcium channel antagonist verapamil, which suggests that transarcolemmal calcium influx contributed to this dysfunction.

It is known that rapid and irregular depolarizations can increase free intracellular calcium in cardiac myocytes of many different species [8]. Piot and coworkers showed that high frequencies of depolarization in human atrial myocytes induced upregulation of cardiac calcium currents, resulting in up $80 \%$ increases in calcium influx [9]. These increased levels of intracellular calcium could shorten the action potential by opening of calcium dependent chloride currents [10-14].

Dynamic of calcium affects calcium activated transmembrane currents like calcium-activated chloride current $\mathrm{I}_{\mathrm{Cl}, \mathrm{Ca}}$.

$\mathrm{I}_{\mathrm{Cl}, \mathrm{Ca}}$ is also known as the second component $\left(\mathrm{I}_{\mathrm{to} 2}\right)$ of a transient outward current $\left(\mathrm{I}_{\mathrm{to}}\right)$ that is active in depolarization. $\mathrm{I}_{\mathrm{Cl}, \mathrm{Ca}}$ magnitude is lower than $\mathrm{I}_{\mathrm{tol}}$, a potassium current, under normal conditions and slow rates. However, at high rates $\mathrm{I}_{\text {to1 }}$ decreases its amplitude and $\mathrm{I}_{\mathrm{to} 2}$ does not. $\mathrm{I}_{\mathrm{Cl}, \mathrm{Ca}}$ is dependent on $\left[\mathrm{Ca}^{2+}\right]_{\mathrm{i}}$, is timeindependent and it presents a voltage-dependent outward rectification [10-13].

We developed a comprehensive model for the $\mathrm{I}_{\mathrm{Cl}-\mathrm{Ca}}$ (published in a previous work)[14] that was included into a rabbit atrial AP model [15]. The present study tries to clarify the role of $\mathrm{I}_{\mathrm{Cl}, \mathrm{Ca}}$ in alternans generation. 


\section{Methods}

A set of mathematical equations describes the dependence of $\mathrm{I}_{\mathrm{Cl}, \mathrm{Ca}}$ on intracellular $\mathrm{Ca}^{2+}$, as well as on ionic concentrations. The current through $\mathrm{Cl}-\mathrm{Ca}$ channels is described as a product of three terms: first term is expressed using the Goldmann-Hodgkin-Katz (GHK) equation, the second term $\left(f_{C a}\right)$ shows the dependence on calcium and follows a Hill-type equation, and the last term ( $R c$ ) shows the rectification exhibited by $\mathrm{Cl}-\mathrm{Ca}$ channels, which is due to a voltage-dependent blockade caused by intracellular cations (Table I).

TABLE I

CALCIUM-DEPENDENT CHLORIDE CURRENT EQUATIONS

$I_{C l, C a}=p c l \cdot f_{C l, C a} \cdot R c \cdot \frac{v \cdot F^{2}}{R \cdot T} \cdot \frac{\left[C l^{-}\right]_{o} \cdot e^{v \cdot F / R \cdot T}-\left[C l^{-}\right]_{i}}{e^{v \cdot F / R \cdot T}-1}$

$f_{C l, C a}=\frac{1}{1+\left(K_{m C l, C a} /\left[C a^{2+}\right]_{i}\right)^{\mathrm{n}_{\mathrm{H}}}}$

$R c=\frac{1}{1+e^{(v-44.4) / 17.2}}$

Model Parameters:

$\mathbf{K}_{\mathrm{mCl}, \mathrm{Ca}}=150,2 \cdot 10^{-3} \mathrm{mM} / \mathrm{l} \quad \mathbf{p c l}=1,1712 \cdot 10^{-3} \mathrm{nS} \quad \mathbf{n}_{\mathbf{H}}=1$

The mathematical description of $\mathrm{I}_{\mathrm{Cl}, \mathrm{Ca}}$ was included into the atrial AP LMCG model.

Software programs were written in ACSL language using Gear stiff algorithm to solve the nonlinear system of differential equations that result from the AP myocyte model.

\section{Results and discusion}

To induce alternans, the pacing cycle length was abruptly shortened from a basic drive of $1000 \mathrm{~ms}$ to $180 \mathrm{~ms}$ after $7.5 \mathrm{~s}$ of stimulation.

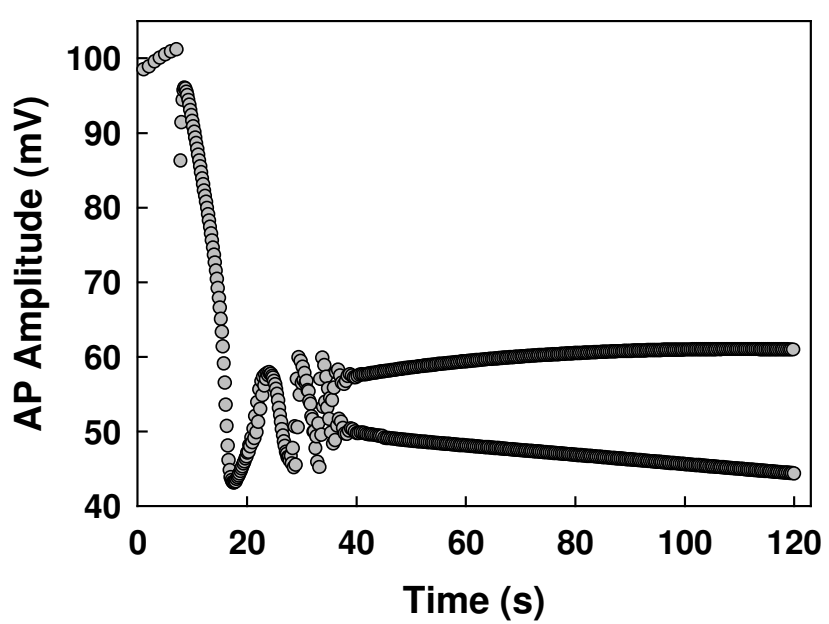

Figure 2. AP amplitude after sudden change in pace rate from cycle length of $1000 \mathrm{~ms}$ to $180 \mathrm{~ms}$ at $7.5 \mathrm{~s}$.

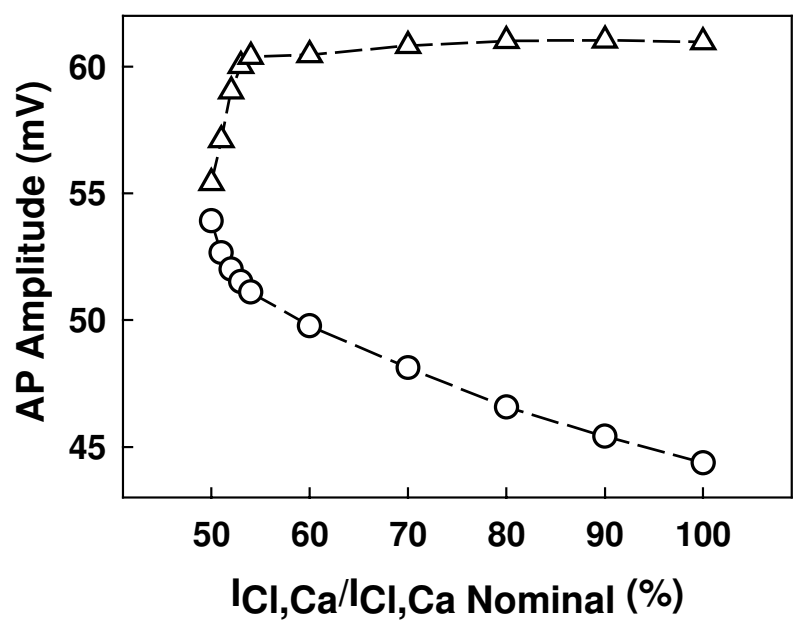

Figure 3. Beat-to-beat AP amplitude alternans (triangle: high and circle: low amplitude) at $120 \mathrm{~s}$ and various $\mathrm{I}_{\mathrm{Cl}, \mathrm{Ca}}$ blockades.

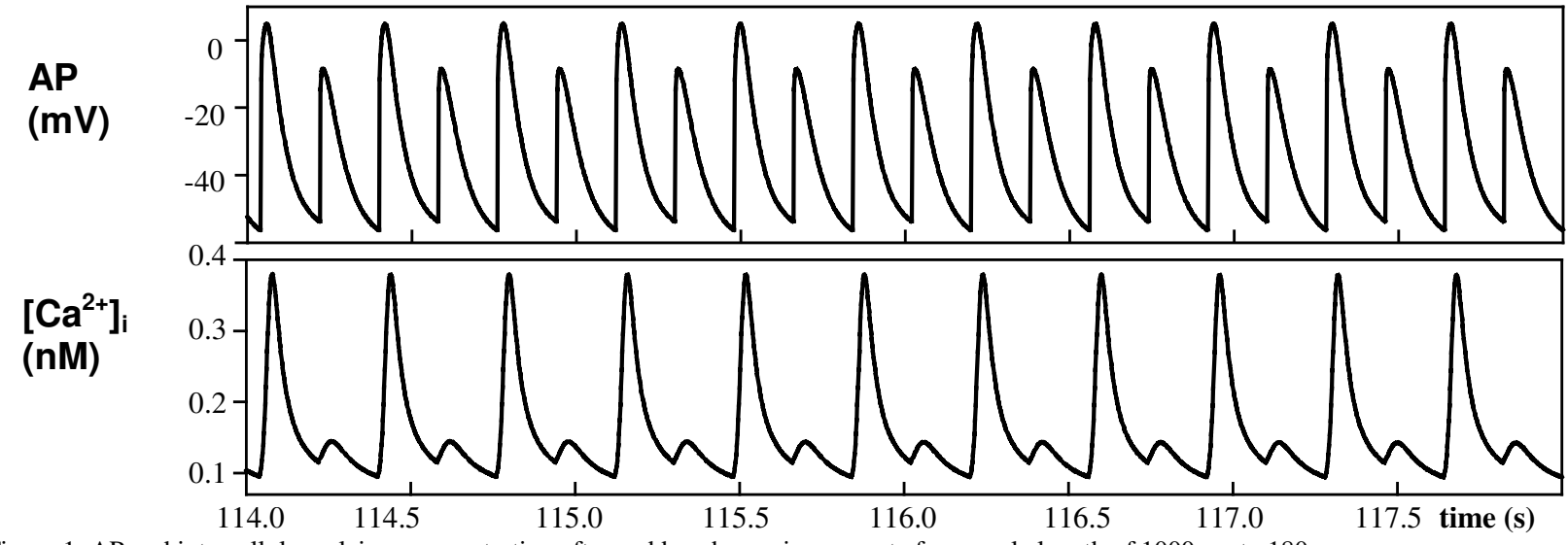

Figure 1. AP and intracellular calcium concentration after sudden change in pace rate from cycle length of $1000 \mathrm{~ms}$ to $180 \mathrm{~ms}$. 

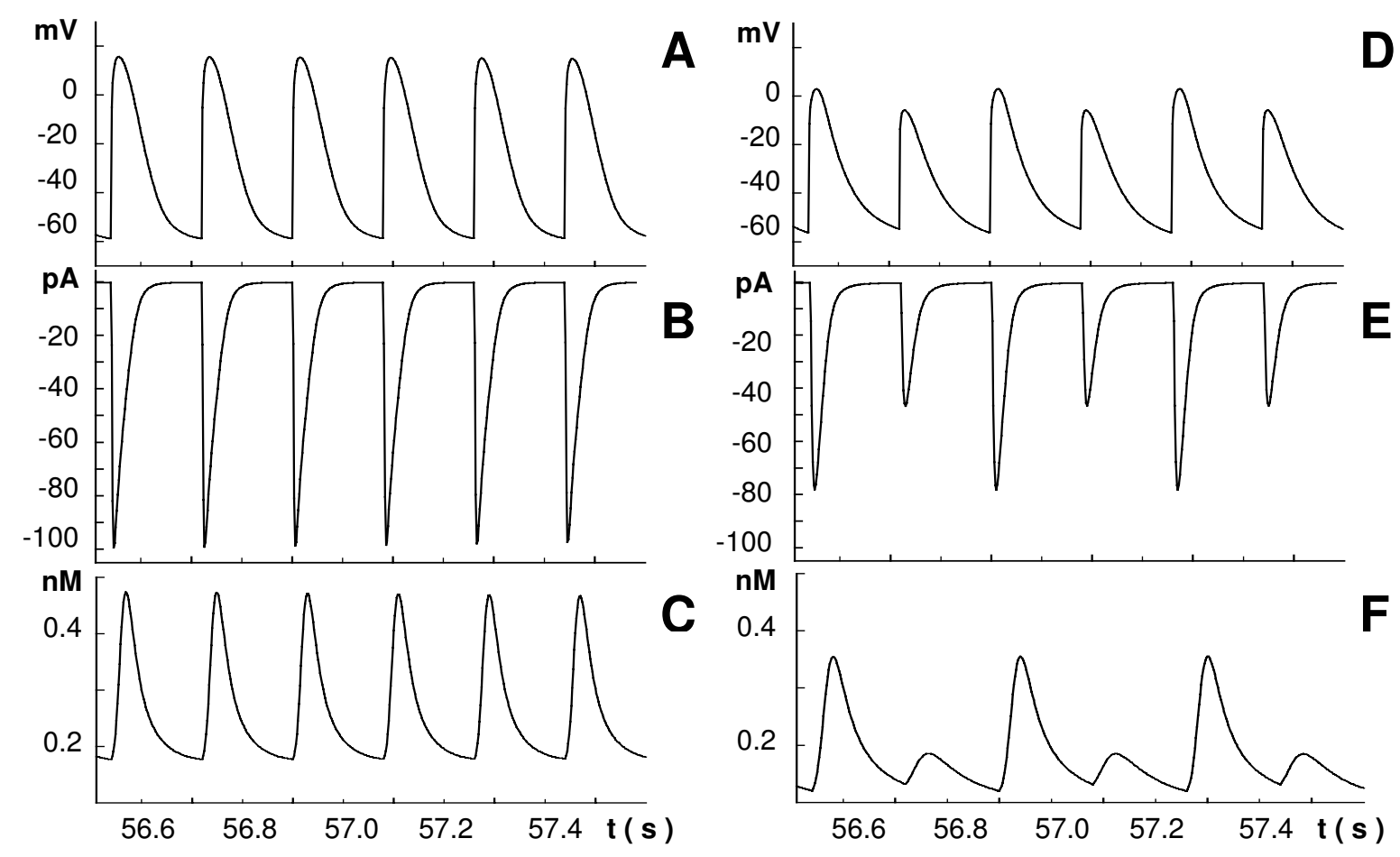

Figure 4. Action potential, L-type calcium current and intracellular calcium concentration, corresponding to control situation (traces D, E and $\mathrm{F}$, respectively) and calcium-activated chloride current blockade (to $40 \%$ of nominal value) situation (traces $\mathrm{A}$, B and $\mathrm{C}$, respectively), after sudden change in pace rate from cycle length of $1000 \mathrm{~ms}$ to $180 \mathrm{~ms}$.

Fig. 1 shows the results of increasing pace rate. In this situation the action potential (after a transient interval) presents beat-to-beat alternation in amplitude $(44 \mathrm{mV}-61 \mathrm{mV})$. The beat-to-beat variations of intracellular calcium $(0.15 \mathrm{nM}-3.7 \mathrm{nM})$ concentration seem to indicate a calcium dynamic correlation with AP alternans.

Fig. 2 shows the variations of action potential amplitude. Plot shows a reduction in amplitude after decreasing cycle length at $7.5 \mathrm{~s}$. It can be observed the presence of a time transient interval between the increase of pace rate instant and steady state. In this transient the action potential amplitude decreases and it arrives to a level around that the final amplitude presents beat-to-beat alternation.

In order to study the role that $\mathrm{I}_{\mathrm{Cl}, \mathrm{Ca}}$ plays we repeat the procedure of alternans inducing (increasing pace rate from a cycle length of $1000 \mathrm{~ms}$ to $180 \mathrm{~ms}$ ) decreasing $\mathrm{I}_{\mathrm{Cl}, \mathrm{Ca}}$ in the range of 0 to $100 \%$ blockade grades. The beat-to-beat alternation of AP amplitude decrease if $\mathrm{I}_{\mathrm{Cl}, \mathrm{Ca}}$ is blocked.

Fig. 3 shows the variations of action potential amplitude at $120 \mathrm{~s}$ when $\mathrm{I}_{\mathrm{Cl}, \mathrm{Ca}}$ is in the range of 100 to 50 percent of its nominal value. At nominal value (100\%) the difference between high and low AP amplitude is relevant $(44 \mathrm{mV}-61 \mathrm{mV})$. At $50 \%$ of $\mathrm{I}_{\mathrm{Cl}, \mathrm{Ca}}$ nominal value the difference is small $(54 \mathrm{mV}-55 \mathrm{mV})$.
Results corresponding to decrease $\mathrm{I}_{\mathrm{Cl}, \mathrm{Ca}}$ to $40 \%$ of its nominal value (blockade of current: $60 \%$ ) are shown in Fig. 4. Traces A, B and $\mathrm{C}$ respectively show the action potential, the L-type calcium current and the intracellular calcium concentration corresponding to blockade conditions. At the right hand (traces D, E and F) it can be observed the same plots in control situation (at nominal value of $\mathrm{I}_{\mathrm{Cl}, \mathrm{Ca}}$ ).

Fig 4. shows that action potential amplitude does not present beat-to-beat variation in blockade situation. The AP amplitude, L-type calcium current and calcium concentration in blockade situation are higher than similar traces in control situation $(67 \mathrm{mV}, 98 \mathrm{pA}$ and $47 \mathrm{nM} / \mathrm{l}$, respectively).

Studies in isolated canine atrial myocytes showed that dogs subject to chronic atrial tachycardia have important reductions in L-type $\mathrm{Ca}^{2+}$ current $\left(\mathrm{I}_{\mathrm{CaL}}\right)$ and transient outward $\mathrm{K}^{+}$current $\left(\mathrm{I}_{\mathrm{tol}}\right)$ densities, without any change in inward rectifier $\left(\mathrm{I}_{\mathrm{K} 1}\right)$, the rapid or slow delayed rectifiers $\left(\mathrm{I}_{\mathrm{Kr}}\right.$ or $\mathrm{I}_{\mathrm{Ks}}$ ), the $\mathrm{Ca}^{2+}$-dependent $\mathrm{Cl}^{-}$current, or T-type $\mathrm{Ca} 2+$ current [16]. Ionic remodelling provide insight into how AF alters atrial electrophysiology to promote its own maintenance but do not elucidate the substrate that initially supports AF before remodelling occurs. Answering this question, other studies prove that AP alternans lead to conduction block inducing AF [5]. 


\section{Conclusion}

We propose that $\mathrm{Ca}^{2+}$-dependent $\mathrm{Cl}^{-}$current blockade could prevent alternans generation. In order to study this hypothesis we induce alternans generation by increase of pace rate. Our results shown that in control situation alternans appear and in $\mathrm{I}_{\mathrm{Cl}, \mathrm{Ca}}$ blockade situation they do not appear. For this reason, $\mathrm{I}_{\mathrm{Cl}, \mathrm{Ca}}$ blockade could have antiarrhythmic effect preventing AF generation.

\section{Acknowledgements}

This work was partially supported by the Plan Nacional de Investigación Científica, Desarrollo e Innovación Tecnológica del Ministerio de Ciencia y Tecnología of Spain (TIC 2001-2686).

\section{References}

[1] Waktare JE, Camm AJ. Acute treatment of atrial fibrillation: why and when to maintain sinus rhythm. Am J Cardiol 81: 3C-15C, 1998.

[2] Waktare JE. Cardiology patient page. Atrial fibrillation. Circulation 106: 14-16, 2002.

[3] Moe GK, Abildskon JA. AF as self-sustained arrhythmia independent of focal discharge. Am Heart J 58: 59-70, 1959.

[4] Scherf D, Romano FJ. Experimental studies on auricular flutter and auricular fibrillation. Am Heart $J$ 36: 241-251, 1948.

[5] Narayan SM, Bode F, Karasik PL, Franz MR. Alternans of atrial action potentials during atrial flutter as a precursor to atrial fibrillation. Circulation 106: 19681973, 2002.

[6] Shimizu W, Antzelevitch C. Cellular basis for long QT, transmural dispersion of repolarization, and torsade de pointes in the long QT syndrome. J Electrocardiol 32 Suppl: 177-184, 1999.

[7] Leistad E, Aksnes G, Verburg E, Christensen G. Atrial contractile dysfunction after short-term atrial fibrillation is reduced by verapamil but increased by BAY K8644. Circulation 93: 1747-1754, 1996.

[8] Zygmunt AC, Maylie J. Stimulation-dependent facilitation of the high threshold calcium current in guinea-pig ventricular myocytes. J Physiol 428: 653-671, 1990.

[9] Piot C, Lemaire S, Albat B, Seguin J, Nargeot J, Richard S. High frequency-induced upregulation of human cardiac calcium currents. Circulation 93: 120-128, 1996.

[10] Zygmunt AC, Gibbons WR. Calcium-activated chloride current in rabbit ventricular myocytes. Circ Res 68: 424437, 1991.

[11] Zygmunt AC, Gibbons WR. Properties of the calciumactivated chloride current in heart. J Gen Physiol 99: 391414, 1992.

[12] Collier ML, Levesque PC, Kenyon JL, Hume JR. Unitary $\mathrm{Cl}$ - channels activated by cytoplasmic $\mathrm{Ca} 2+$ in canine ventricular myocytes. Circ Res 78: 936-944, 1996.

[13] Wang Z, Fermini B, Feng J, Nattel S. Role of chloride currents in repolarizing rabbit atrial myocytes. Am J Physiol 268: H1992-H2002, 1995.

[14] Gomis-Tena J, Saiz J. Role of Ca-activated Cl currents in the heart: a computer model. Computers in Cardiology 26: 109-112, 1999.

[15] Lindblad DS, Murphey CR, Clark JW, Giles WR. A model of the action potential and underlying membrane currents in a rabbit atrial cell. Am J Physiol 271: H1666H1696, 1996.

[16] Yue L, Feng J, Gaspo R, Li G-R, Wang Z, Nattel S. Ionic remodeling underlying action potential changes in a canine model of atrial fibrillation. Circ Res 81: 512-525, 1997.

Address for correspondence.

Julio Gomis-Tena Dolz

Centro de Investigación e Innovación en Bioingeniería

U.P.V. Departamento de Ingeniería Electrónica. E.T.S.I.I.

Camino de Vera 14

46071 Valencia.

Spain.

e-mail: jgomiste@eln.upv.es 